FACTA UNIVERSITATIS

Series: Mechanical Engineering Vol. 16, N² 2, 2018, pp. 203 - 217

https://doi.org/10.22190/FUME180403017K

Original scientific paper

\title{
INVESTIGATION OF THE ENERGY RECOVERY POTENTIALS IN VENTILATION SYSTEMS IN DIFFERENT CLIMATES
}

\section{UDC 697}

\author{
Miklos Kassai ${ }^{1}$, Laszlo Poleczky ${ }^{1}$, Laith Al-Hyari ${ }^{1}$, Laszlo Kajtar ${ }^{1}$, \\ Jozsef Nyers ${ }^{2,3}$ \\ ${ }^{1}$ Department of Building Service Engineering and Process Engineering, \\ Budapest University of Technology and Economics, Hungary \\ ${ }^{2}$ Doctoral School of Applied Informatics and Applied Mathematics, \\ Obuda University Budapest, Hungary \\ ${ }^{3}$ Doctoral School of Mechanical Engineering, Szent István University, Hungary
}

\begin{abstract}
The aim of this research study was to investigate the energy recovery potentials in ventilation systems under different climatic conditions. The well-known heating degree day from the literature was updated using the weather data of cities with different climates from the past 40 years. As the novelty of this research with the developed procedure drawn up in this study, the energetic possibilities of heat recovery under various climate and operating conditions may be examined in more detail and more realistically than with the methods and available information of current engineering practices. To achieve this long-term and high definition the weather data of several cities are processed in order to evaluate the possibilities of heat recovery on a daily and annual basis.
\end{abstract}

Key Words: Heat Recovery, Energy Recovery, Degree Day, Enthalpy-hour, Weather data, Different climates

\section{INTRODUCTION}

The basic principle of modern engineering practice is an energy efficient design and operation [1-3]. Significant energy recovery is possible from ventilation equipment in the case of proper choice of equipment and operation [4-9]. Considering the selection of heat recovery equipment, the duration of economic returns is of key importance since an

Received April 03, 2018 / Accepted June 07, 2018

Corresponding author: Miklos Kassai

Budapest University of Technology and Economics, Muegyetem rkp. 3., H-1111 Budapest, Hungary

E-mail: kas.miklos@gmail.com 
investment in integrating heat recovery equipment into the ventilation system only becomes reasonable with adequate energy savings [10-13]. Therefore, it is essential to use the most accurate dimensioning data in the course of design work so that under the given climate conditions, the designer may provide the closest estimate regarding the expectable energy saving [14-18]. In the course of design works it is difficult to provide an accurate estimate with regards to the energy saving of planned heat recovery equipment since a number of parameters influence the performance of such equipment. The working point of heat recovery equipment may vary along a wide scale depending on climate conditions [19-20]. Different types of equipment operate at various rates of effectiveness within such ranges, and the dependence of their exact characteristics on operating parameters is rarely known even by the manufacturers [21]. In the course of building engineering design, an energy recovery ventilation unit is selected in most cases based on the data provided in manufacturers' catalogues, or standards.

The ventilation technology describes the specific energy content of moist air mass per unit with the help of total specific enthalpy, $\mathrm{h}_{\mathrm{T}}$. The energy content of moist air mass per unit depending on physical parameters can be calculated with the help of specific enthalpy - referred to as enthalpy in the following.

The total enthalpy of moist air can be described with the following equation [22]:

$$
\mathrm{h}_{\mathrm{T}}=\mathrm{h}_{\mathrm{S}}+\mathrm{h}_{\mathrm{L}}=\mathrm{C}_{(\text {pa,dry })} \cdot \mathrm{t}+\mathrm{x}\left(\mathrm{r}_{0}+\mathrm{C}_{\mathrm{pa} \text {,wet }} \cdot \mathrm{t}\right)[\mathrm{J} / \mathrm{kg}]
$$

According to Eq. (1) the total enthalpy of moist air, $\mathrm{h}_{\mathrm{T}}$, is made up of a sensible, $\mathrm{h}_{\mathrm{S}}$, and a latent $\mathrm{h}_{\mathrm{L}}$, in $[\mathrm{kJ} / \mathrm{kg}]$ component. In Eq. (1), $\mathrm{C}_{\mathrm{p}}$ represents the specific heat capacity of the dry and wet air in $[\mathrm{kJ} / \mathrm{kg} \mathrm{K}]$ on constant pressure $\mathrm{p}$; $\mathrm{t}$ represents the temperature in $[\mathrm{K}]$; $\mathrm{x}$ represents the absolute humidity contact of the air in $[\mathrm{kg} / \mathrm{kg}]$ and $\mathrm{r}_{0}$ is the phase change heat in $[\mathrm{kJ} / \mathrm{kg}]$. In the course of interaction of moist air streams with different enthalpies sensible (thermal), or thermal and latent heat exchange may occur. The purpose of heat recovery units - referred to as HRU in the following - is to provide thermal, or thermal and latent heat exchange between two moist air streams with different enthalpies at the highest possible rate of effectiveness. The application of HRU-s in the ventilation technology enables ambient air to be preheated during the heating season, or to be pre-cooled during the cooling season using the recovered portion of heat loss from discharged air. In this way the reasonable energy consumption of auxiliary heating/cooling coils providing the indoor condition of air within the supplied space may be significantly decreased. In the following, heat recovery system components shall be interpreted according to the definitions of VDI 2071 [23], as shown in Fig. 1. Recirculation of air, or cooling/heating with waste heat is not considered as heat recovery according to the interpretation of [2].

The amount of recovered heat primarily depends on the heat content of ambient air conditions (depends on climate conditions) and exhaust air conditions and the effectiveness of heat recovery (given by the producer), as shown in Fig. 2 as well. Higher temperature difference, relative humidity difference or enthalpy difference between the ambient air and exhaust air results in higher energy recovery. The position of the time interval of heat recovery within the given day is also of key importance since the enthalpy content of ambient air varies according to the time of the day depending on the given climate. The effectiveness of heat recovery of HRU-s varies depending on operating conditions (volumetric air flow, temperature, relative humidity, drum rotation, frosting, condensation, 
etc.). Effectiveness rates given by manufacturers apply to the indicated conditions of operation, and are less applicable in the case of different conditions. Due to unknown equipment characteristics, dimensioning, selection and energetic classification of units are based on average annual effectiveness of heat recovery. Continuously changing conditions, i.e. the effect of outdoor air conditions with known equipment characteristics could only be examined using a simulation program. In the course of this research the possibilities of heat recovery are obtained to investigate by processing high resolution weather data. The final objective is to construct tools suitable for longer term energetic estimations, with the help of which the variation of theoretically recoverable heat within ventilation units using ambient air can be demonstrated depending on the parameters of operation, such as indoor air temperature $\approx$ temperature of exhaust air, the time interval of operation, and weather related expectations. The purpose of evaluated weather data is to determine the theoretically recoverable sensible, latent and total energy depending on the above mentioned variables.

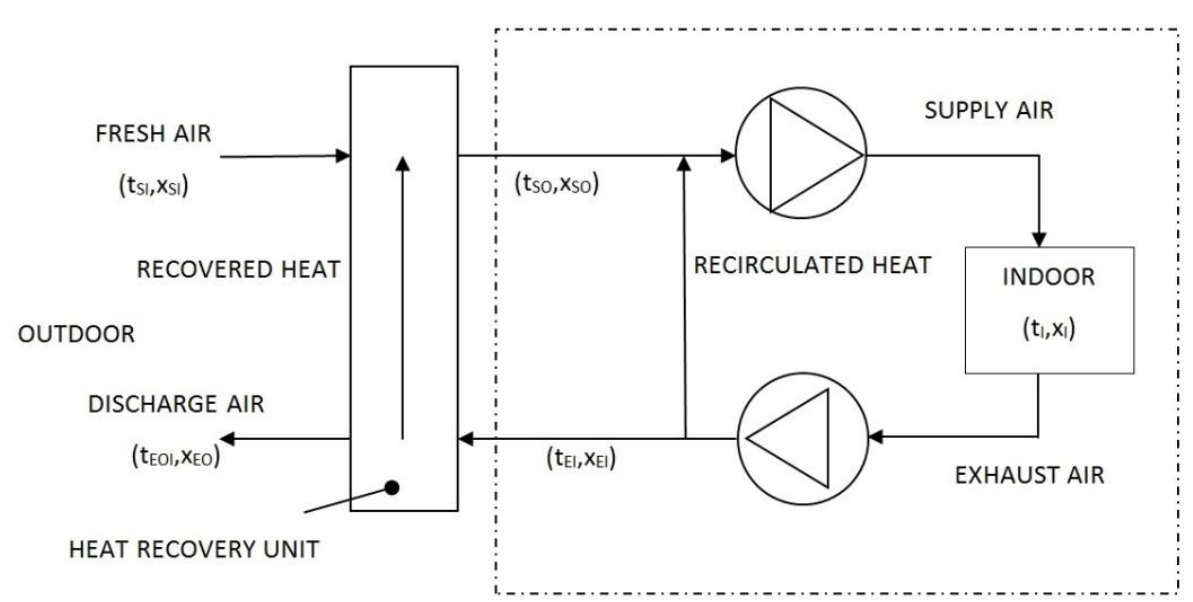

Fig. 1 Diagram of the heat recovery process [23]

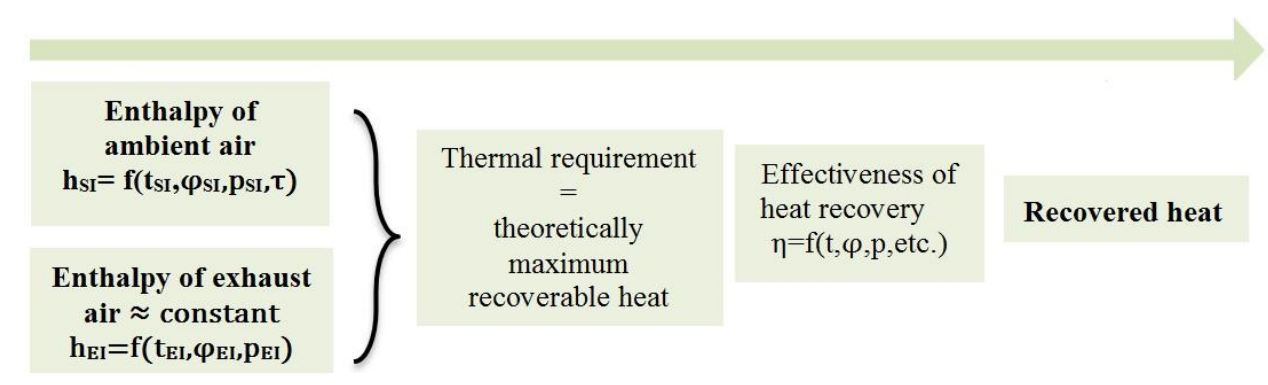

Fig. 2 Components of the heat recovery process

As the novelty of this research with the developed procedure drawn up in this study, the energetic possibilities of heat recovery under various climate and operating conditions may be examined in more detail and more realistically than with the methods and available information of current engineering practices. 


\section{THE DESCRIPTION OF THE DEVELOPED PROCEDURE}

Examined cities were selected on the basis of diversity of their climates, within the possibilities offered by the Wolfram Alpha database. The colors of Fig. 3 show the location of examined cities according to the Koppen type [24] climate zones.

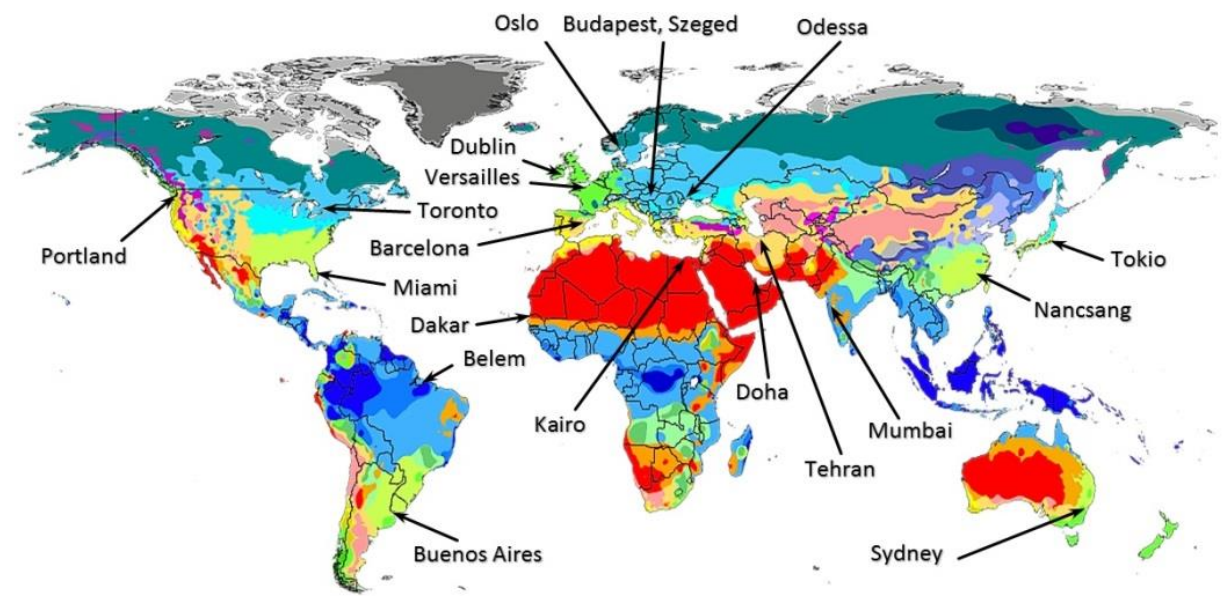

Fig. 3 Location of investigated cities according to the Koppen type climate zones [25]

Moreover, Fig. 4 shows the distribution of climate regions of Hungary as one of the investigated countries.
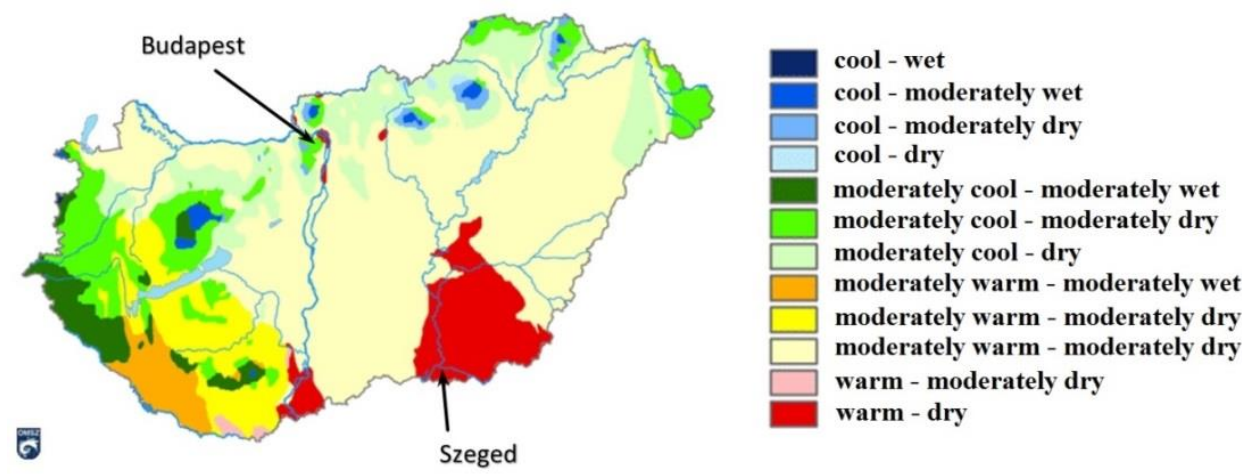

Fig. 4 Climate regions of Hungary according to the Koppen type climate zones [25]

In the course of this research, from among the components presented on Fig. 2, the heat content of ambient air was evaluated by month and by hours of the day based on the following concept: the theoretically recoverable maximum heat is the difference of the sum of areas (integrals) under the enthalpy curve of ambient air and the enthalpy line of exhaust air for the period in question. Available indicators of the condition of ambient air however, are deficient in a different degree per section. Therefore, they can only be used 
for determination of time dependent integral sums after correction or simplification/ generalization. As an initial approach the partly defective data sequences were attempted to correct by substituting in the missing values, yet this significantly distorted the original sample. As a second approach, with the omission of defective parts fewer samples were ended up; however, these were more representative of the examined phenomena due to the originality of data. By taking the average of data sequences for the same times of day with minimal correction, the change in the distribution of data, the mean values is negligible.

The idea behind the evaluation method is the following: let us assume that one unit will only be operated for a one hour period each year on the 1st of January between 1:00 and 2:00 o'clock. Parameter values characterizing ambient air are different every year at that time. Performing the calculation for many years one by one, then adding and taking the average of the parameters characterizing ambient air, it may be determined what the expectable value of the given parameter is on average if normal distribution is assumed. With the same idea, average days can also be constructed for each month from such elemental hours as follows: all hours of an average day characteristic of the month will be the mean value of the values measured at the same time of the same day in the same month of all years. Accordingly, with the method applied in the research, from these average days, such average months and an average year can be constructed, which on the basis of the examined years provides an estimate related to the given hour, or given month that can be used in terms of energetics. In the course of estimation, from the increasing sequence of values of a given hour, the limit value of any range can be selected as standard. With a division into 10 sections, decile limit values were determined. In this way 10 values were recorded for the hours of the average day of each month. The lower and upper limit values of such decile sequence represent the registered minimum and maximum values where the middle element is the mean value. In the further step of evaluation, with the use of data sequences constructed from the decile values varying from such mean value, the effect of weather values different from the average could also be taken into consideration. This is highly important since the working points of HRU-s may vary within these ranges, as mentioned before. Consequently, in addition to an average energetic characterization, it is possible to determine the expectable minimum and maximum operating conditions, the range of heat recovery values as well.

In the course of this research the weather data of 40 years of Budapest, and of 20 years of further 19 cities are processed with different climates using the downloading and evaluation programs described in Wolfram Mathematica 11.0. The purpose of evaluation was to determine an average daily temperature, relative humidity, pressure and total/sensible/latent enthalpy sequences projected to a month, to end up with 10 decile curves per parameter. The data sequences belonging to a given decile value are indicated as: No. i - decile value $\rightarrow$ (i-1)100 [\%]. Accordingly, the first decile was marked as 0 [\%], the last one as 100 [\%]. This is to mean that according to the previous method of evaluation it can be established that of the data population available for the given time 0 [\%] is located below the first decile, and $100[\%]$ between the first and the tenth decile. Thus the resulting [\%] marked decile curves mean a range constructed on the basis of data measured in the past, from among which it is practical to select the data used for dimensioning. The average expectable value is equivalent to the $50[\%]$ marked decile curve, while the maximum and minimum expectable values can be found on the $100[\%]$ and $0[\%]$ marked curves, respectively. The prepared energetic estimate is valid for a long term while for a short term the heat content of ambient 
air varies around the 50 [\%] marked decile data sequence, within the 0 and 100 [\%] decile range. The long term average value of variation can also be interpreted in terms of energetics with consideration to the $50[\%]$ decile curves. Therefore the method can only be used accurately for a long term estimation while for a short term it shows the expectable interval of the variation of values based on past events.

In the course of specification of enthalpy curves, instead of the average daily sequences, the matching value triads of the original data sequence were applied. This is important since the value triads cannot be considered as independent variables in this respect. The given enthalpy sequences will accordingly contain the average joint product of the matching air temperature - relative humidity - pressure (referred to as t- $\varphi-p$ ) value triads, which is not equivalent to the individually taken average values of variables at the given time since enthalpy is not a linear resultant of the given parameters. Decile data sequences were derived from the enthalpy sequences for the given times using the previously described method.

Previously introduced decile curves will be referred to as expectations in the following since with the use of decile data sequences different from the average, we have positive or negative expectations with respect to the non-average heat content of ambient air. The theoretical process of evaluation is represented in Fig. 5. In this way the operation of the enclosed program parts is more illustrative and easier to follow.

For the generation of reliable monthly average (t- $\varphi-p)$ graphs from the data sequences of adequate density, certain conditions had to be defined before the evaluation of daily data sequences. In the case of examined cities, the data sequences of all days were omitted from the evaluation where the following two conditions were not met with respect to any of the given daily $(\mathrm{t}-\varphi-\mathrm{p})$ lists:

1) A daily minimum expectation of 6 measurements can ensure that two adjacent pieces of data are no more than 4 hours apart on average. This is required for the interpolation in the course of enthalpy calculation. Accordingly, all data sequences must contain at least 6 pieces of recorded data.

2) The first and last piece of data of the day can be no more than 4 hours apart from the beginning, or end of the given day respectively, thus any missing value for 00:00 and 24:00 hours could be reliably interpolated or substituted.

The number of omitted days is represented for each city in relation to the examined time period and based on average annual distribution. A constant exhaust air temperature and humidity were assumed with a fresh-air system. The examined fresh-air ventilation system does not heat/cool, it only ensures an air supply to the premises at the prescribed temperature while all other thermal requirements are ensured by other building engineering systems. In this way the temperature of exhaust and supply air can be considered as equivalent. The effects of frosting, condensation, maintenance, etc., which decrease operating times, were also omitted. 


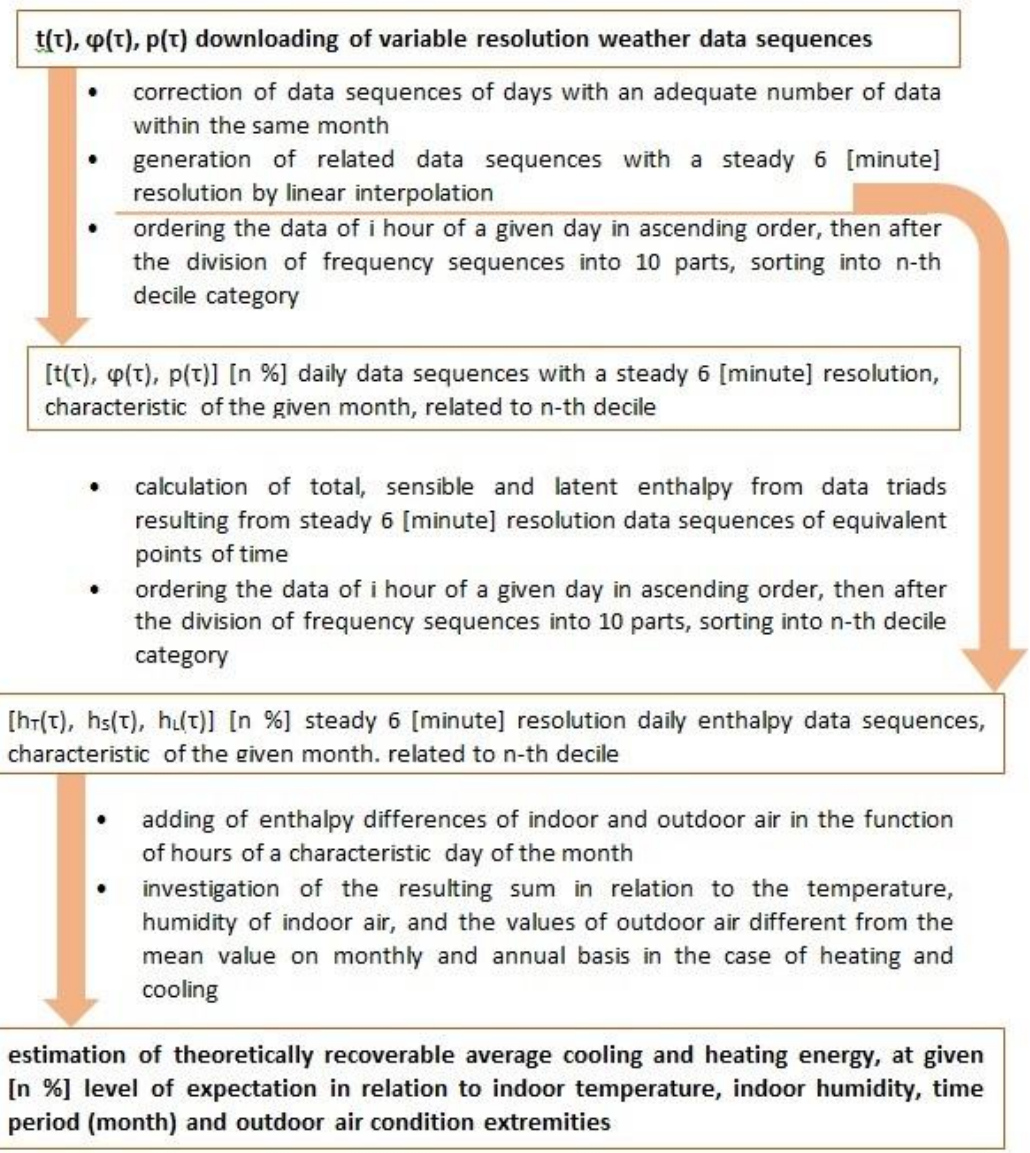

Fig. 5 The theoretical process of evaluation

\section{PResentation of the Evaluation Method}

In the following paragraphs the most significant results of weather data are presented evaluated with the developed program using the above described method, for each city.

The amount of recoverable heat was summed separately for cooling and heating modes of operation since in this way the decrease in the energy requirement of the cooling calorifier and heating calorifier can be viewed separately for the given month. Recoverable heat during one month of the presented graphs is the product of values of an average day characteristic of the given month, by the number of days in the given month.

The expectable percentage value of total recoverable energy was calculated for each month with 50 [\%] expectation for an exhaust air condition of $22\left[{ }^{\circ} \mathrm{C}\right]$ and 50 [\%]. Heat amounts representative of months were represented in percentage of annual heat amounts, so as to reflect the distribution of annually recoverable heat through the months of the year. 
The percentage value shown on the top section of graphs shows the marking of the applied decile sequence, while the Celsius value shows the temperature value of exhaust air considered as constant. The humidity of exhaust air was considered as 50 [\%] in all cases. Considering the limitation of the length of the paper one of the investigated cities Barcelona [16] was selected to present the detailed results (Figs. 6-10). In the end of the evaluation, the expected annually recoverable thermal energy of all 20 cities is compared on a single graph investigated by the developed method used for Barcelona analogically.

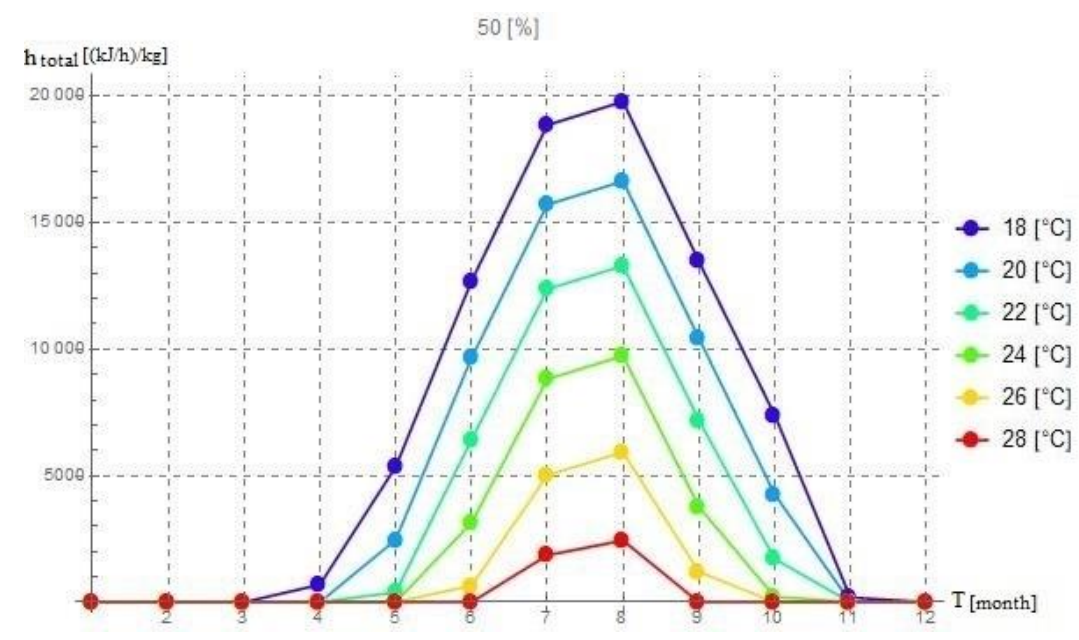

Fig. 6 Expected recoverable monthly total cooling enthalpy-hour in relation to the temperature of exhaust air

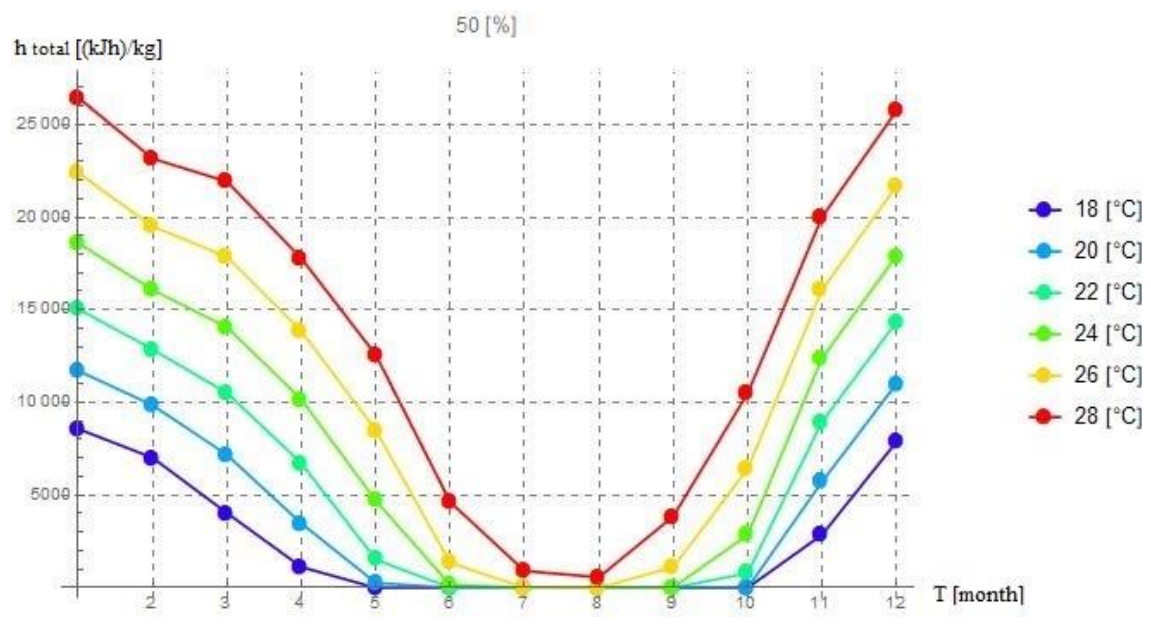

Fig. 7 Expected recoverable monthly total heating enthalpy-hour in relation to the temperature of exhaust air 


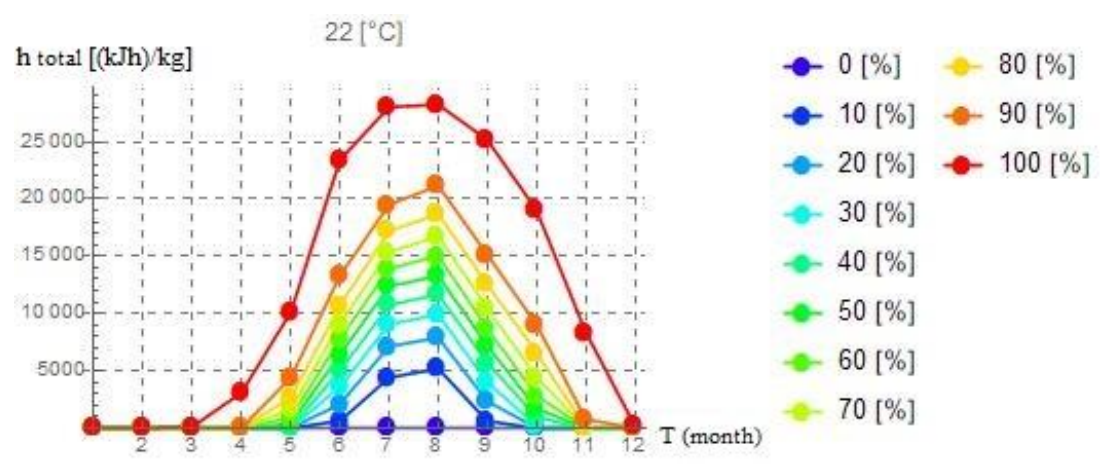

Fig. 8 Recoverable monthly total cooling enthalpy-hour in relation to the expectation

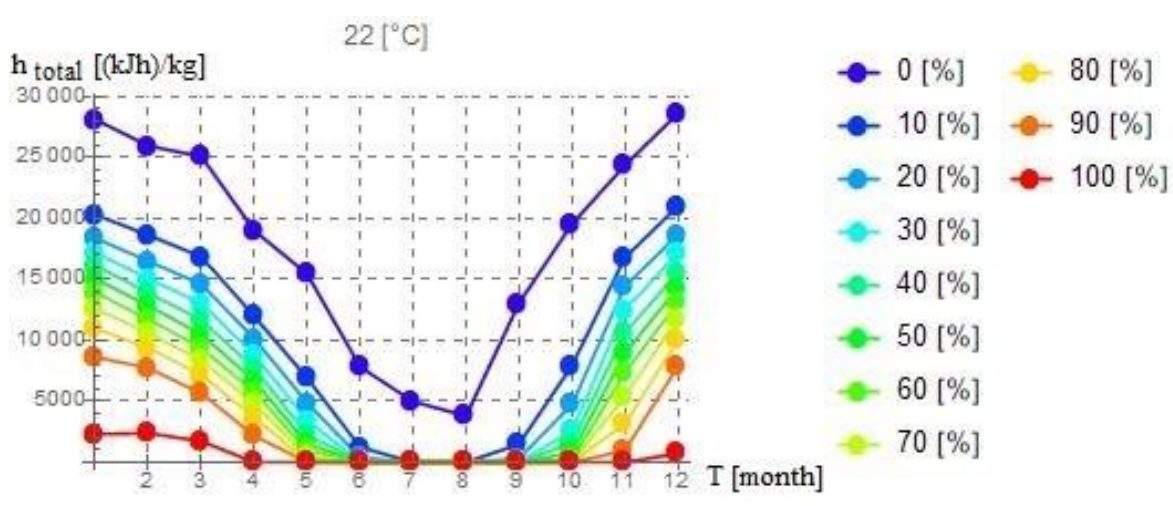

Fig. 9 Recoverable monthly total heating enthalpy-hour in relation to the expectation

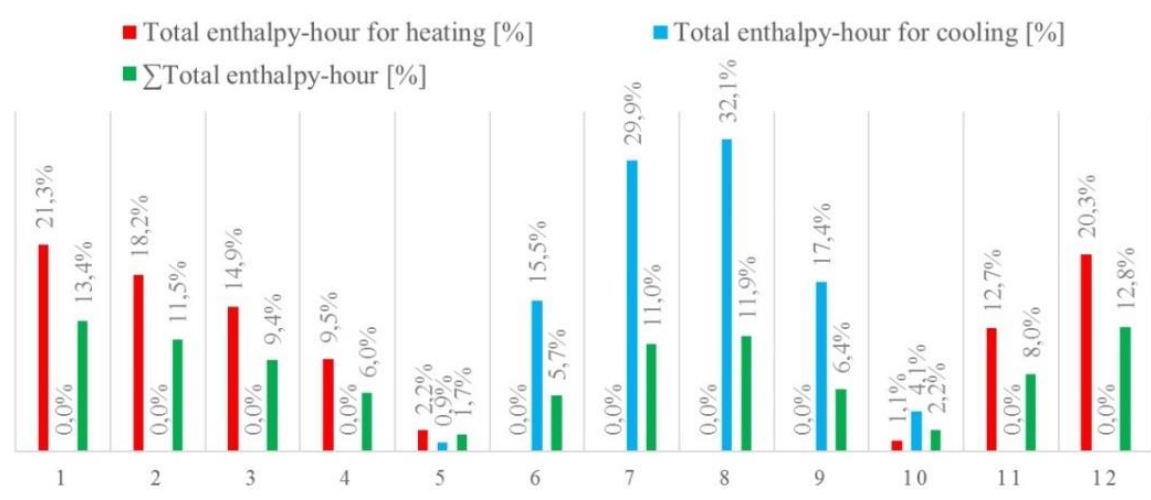

Fig. 10 Monthly distribution of expected annually recoverable total enthalpy-hour based on the past 20 years with 50 [\%] expectation

Figs. 6-10 show that a major part of cooling energy recovery occurs between the months of June and October in Barcelona. The temperature of exhaust air significantly influences the expected recoverable heat amount during the intermediate period (May and 
October). Expectable annual total, sensible and latent enthalpy-frequency graphs show the annually expectable hours of equipment operation in heating and cooling modes at 50 [\%] expectation with known values of total, sensible and latent enthalpy of exhaust air. With such time periods and the recoverable total/sensible/latent heat amounts at hand, the optimal heat/energy recovery unit type can be selected in the designing phase previously based on its estimated annual sensible and latent rates of effectiveness. The length of time periods with respect to the remaining cities shall be established in accordance with the method described here while due to the limited space, only the expectable annual total enthalpy-frequency graphs for the city of Barcelona (Fig. 11) shall be included in the publication. Using the developed diagram (Fig. 11) the expectable total heating-cooling period can be easily determined (e.g. following the black colored line, this period is around 5120 hours with $43 \mathrm{~kJ} / \mathrm{kg}$ total enthalpy of exhaust air and under 50 [\%] expectation for Barcelona). The summary graph showing the values of all cities (Fig. 15) is given in the results section of this paper.

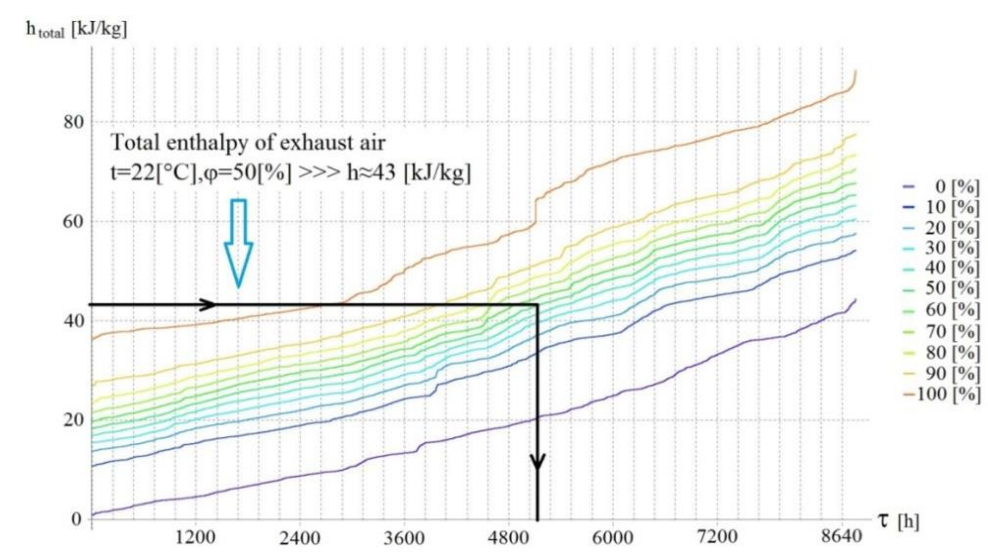

Fig. 11 Expectable annual total enthalpy-frequency graph

\section{THE EFFECTS OF EXHAUST AIR TEMPERATURE AND TIME INTERVAL OF OPERATION ON EXPECTED THEORETICAL MAXIMAL MONTHLY RECOVERABLE THERMAL ENERGY}

Investigation of the effects of the time interval of operation is a complex task. The average daily time-dependant recoverable thermal energy for the given month was determined as follows. Using the average daily enthalpy sequences of the given month, the recoverable heat amounting up to the given hour was calculated in each half-hour where the enthalpy of exhaust air was given as a function of air condition indicators of exhaust air. Thus the algorithm shown in Fig. 5 performed the computation of recoverable thermal energy assigned to every half-hour of average monthly days in the function of the expectation (decile curve), and the temperature and humidity of exhaust air. Figs. 12-14 show the expected recoverable latent heat amount of Barcelona in the month of December. The developed evaluation algorithm constructed the above shown graphs for all cities and all months, allows the expectable heat recovery in a month of any given city within the selected time interval of operation to be determined with a given expectation (decile). 


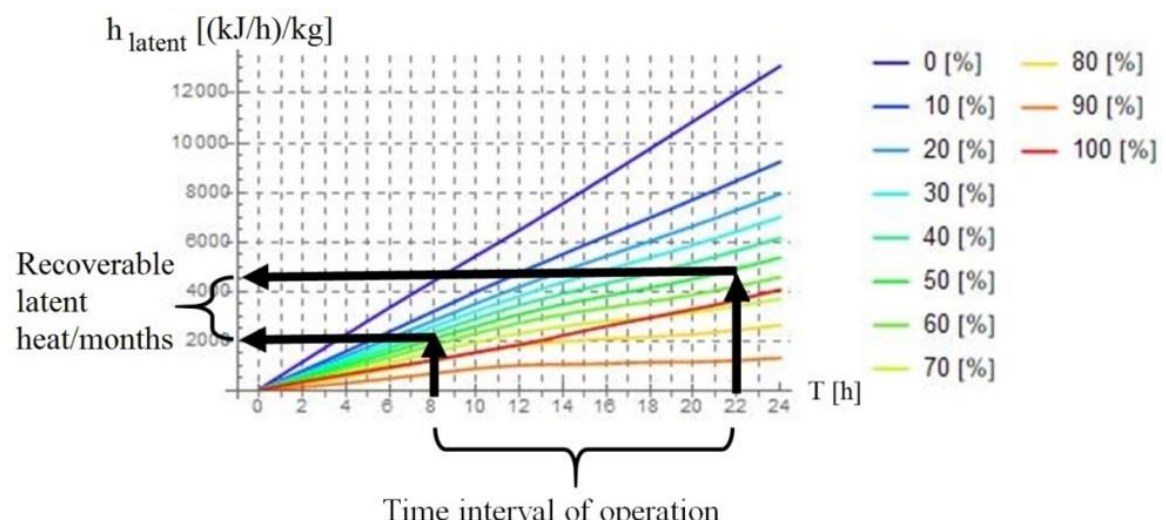

Fig. 12 Expected monthly recoverable latent heat in the function of the expectation and the time interval of operation

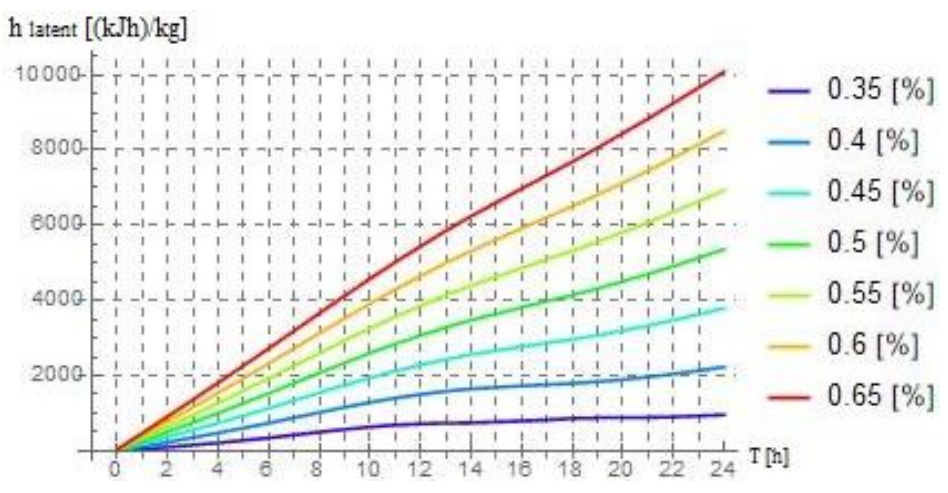

Fig. 13 Expected monthly recoverable latent heat in the function of exhaust air temperature and the time interval of operation

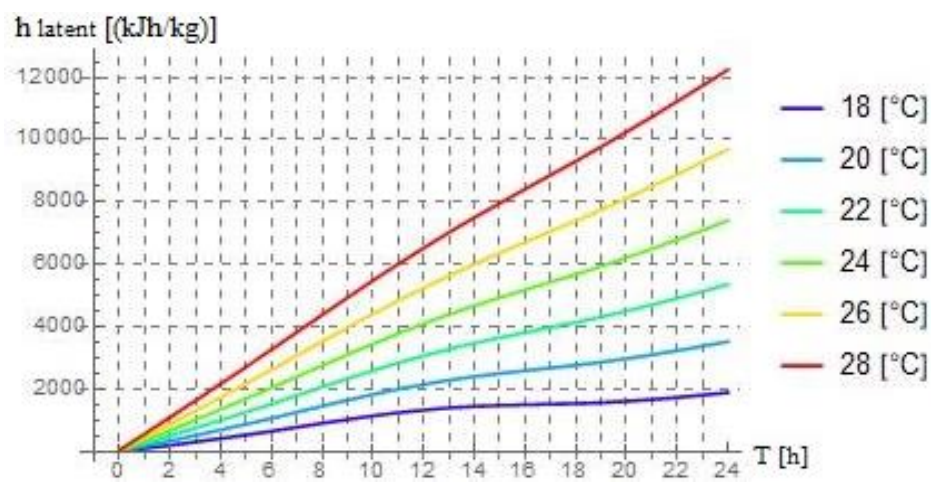

Fig. 14 Expected monthly recoverable latent heat in the function of humidity of exhaust air and the time interval of operation 
The resulting graph represents a given month, showing the limits of the time interval of operation on the horizontal axis, and the recoverable heat amount up to the given point of time on the vertical axis in the function of parameters of exhaust air, with the given expectation. After the time interval of operation is determined, the difference of " $y$ " values of the respective curves will provide the heat amount recoverable during the given time interval.

Based on the previous figures it can be concluded that even a slight change of enthalpy of exhaust air may significantly modify the length of heating/cooling time periods relevant in terms of heat recovery. This finding is supported by the above figures entitled "Expected monthly recoverable total cooling enthalpy-hour in the function of exhaust air temperature", and the enthalpy-frequency graphs of cities. Fig. 12 shows that the expected monthly recoverable heat amount is quite sensitive to the changes of exhaust air, even ten-times deviation can result in the monthly summary. According to the generated graphs, this sensitivity varies according to city and periods of time, yet it is significant in all cases.

Using the method described for the city of Barcelona, the length of expected total, sensible and latent heating/cooling periods were established for all cities. The values and their annual percentage proportions can be compared on the basis of Fig. 15. Total hours of operation are naturally the sum of heating and cooling hours, i.e. the empty section up to the 100 [\%] value above all bars represents the percentage value of the respective cooling energy recovery hours of operation. Fig. 15 shows the amount of the maximal, theoretical energy that can be recovered from the exhaust air during the ventilation operation in each investigated cities.

Values of Fig. 15 can be used for the selection of an adequate heat/energy recovery. The method of such selection shall be the subject of future research work.

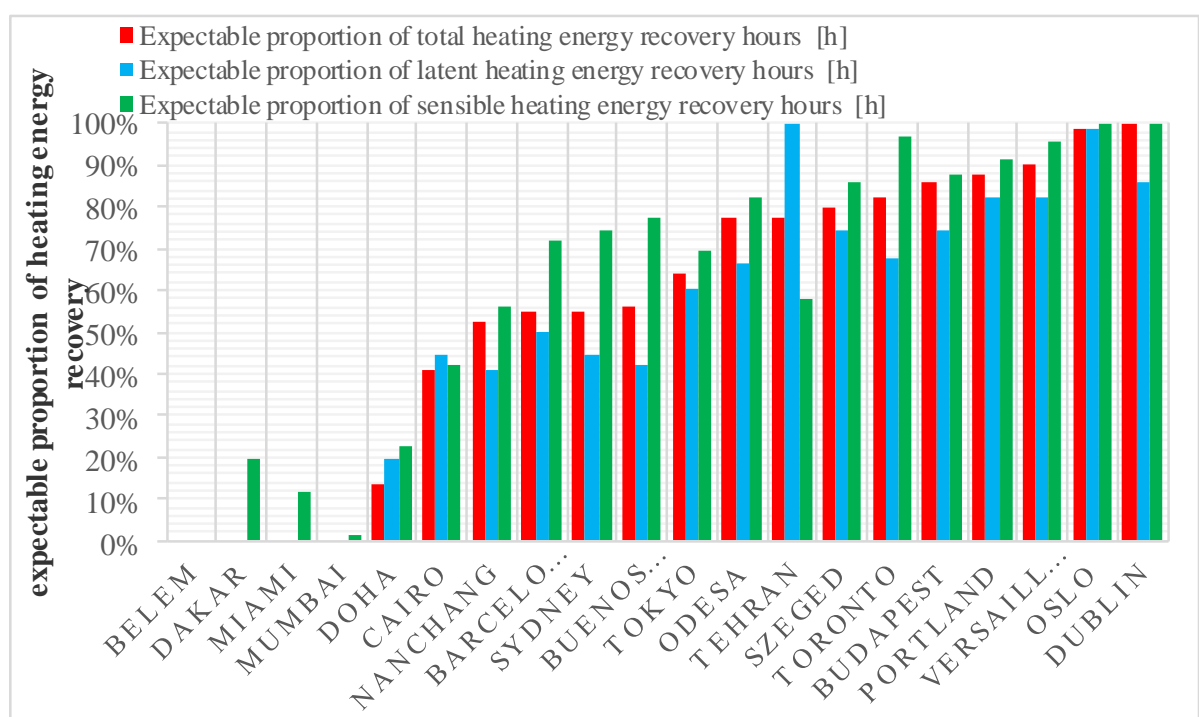

Fig. 15 Annual expectable proportion of heating energy recovery hours per city 


\section{RESULTS}

Based on a comparison of the expected annually recoverable thermal energy of examined cities, a sequence of cities can be drawn up on the basis of expected total recoverable thermal energy revealing unexpected similarities which are not necessarily predictable from the climate zones of the given cities (Fig. 16).

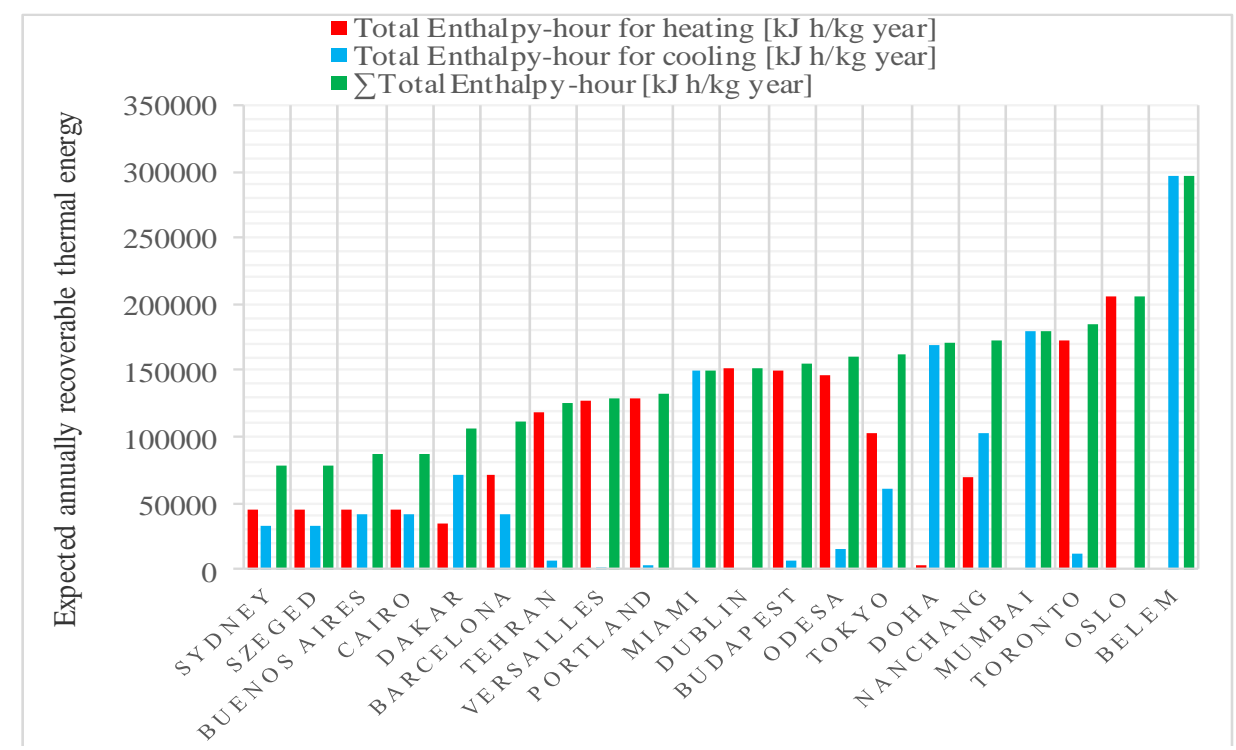

Fig. 16 Expected annually recoverable total, sensible and latent thermal energy per city

Fig. 16 shows that Budapest is in a favorable position within the sequence, and a major portion of energy recovery occurs in heating mode of operation. From among all cities, Belem is outstanding, where heat recovery during the cooling period exceeds the annual amount experienced in all other cities. The least amount of energy can be saved in Sydney, while the amount of savings is not negligible.

The energetic similarity is shown between Sydney, Szeged, Buenos Aires, Cairo, Dakar and perhaps even Barcelona and Nanchang, with a similar magnitude of recoverable energy amounts during the heating and cooling seasons.

Similarly, Tehran, Versailles, Portland, Dublin, Budapest, Odessa, Toronto and Oslo can be ranked together where the expected recoverable heat amount during the heating season significantly exceeds that during the cooling season.

In the case of Miami, Doha, Mumbai and Belem the opposite applies, yet expected heat recovery is significant in these cities during the cooling season. 


\section{CONCLUSION}

The above findings apply to a constant $22\left[{ }^{\circ} \mathrm{C}\right]$ temperature and $50[\%]$ relative humidity condition of exhaust air. In the evaluation program these are represented in the function of the enthalpy of exhaust air; this parameter can later be substituted by any arbitrary ambience or indoor parameter. Accordingly, the generated curves can be universally applied for calculations under any static or dynamically changing conditions of exhaust air. The exploitation of this opportunity shall also be the subject of future research work.

Using the developed methods described in this paper a large number of auxiliary tables have been generated on the basis of weather data which may be utilized in the course of design work (refer to Figs. 12-14), and which allow for estimation of the expected realizable energy saving of ventilation equipment in any given month, during any time interval of operation in the function of the temperature and relative humidity of exhaust air, with a given expectation applied decile curve.

Acknowledgements This research was financially supported by the National Research, Development and Innovation Office of Hungary [grant number NKFIH PD 115614].

\section{REFERENCES}

1. Laverge, J., Janssens A., 2012, Heat recovery ventilation operation traded off against natural and simple exhaust ventilation in Europe by primary energy factor, carbon dioxide emission, household consumer price and exergy, Energy and Buildings, 50, pp. 315-323.

2. Laković, M., Pavlović, I., Bajnac, M., Jović, M., Mancić, M., 2017, Numerical consumption and prediction of electricity consumption in tobacco industry, Facta Univesitatis-Series Mechanical Engineering, 15(3), pp. 457-465.

3. Calay, R.K., Wang, W., 2011, A study of an energy efficient building ventilation system, Proceedings of RoomVent 2011: 12th International conference on air distribution in rooms, 19-20 June, Trondheim, Norway, pp. 19-22.

4. Jan, T., Zuzana, S,, Lukáš R., 2018, Analysis of Heating Investments and Operating Costs for Residential Building, Periodica Polytechnica, Mechanical Engineering, 62(1), pp. 10-15.

5. Al-Ghamdi, A. S. 2006, Analisys of air-to-air rotary energy wheels, Phd Thesis.

6. Maclaine-Cross, I.L., 1974, A theory of combined heat and mass transfer in regenerators, Ph.D. Dissertation in Mechanical Engineering, Monash University, Australia.

7. Klein, H., Klein, S.A., Mitchell, J.W., 1990, Analysis of regenerative enthalpy exchangers, International Journal of Heat and Mass Transfer, 33, pp. 735-744.

8. Harmati, L.N.; Folic, Radomir J.; Magyar Z., 2015, Energy Performance Modelling and Heat Recovery Unit Efficiency Assessment of an Office Building, Thermal Science, 19, pp. 865-880.

9. Laith, A.H., Miklos, K., 2018, Energetic Investigation of Energy Recovery Technologies in Air Handling Units. International Review of Applied Sciences and Engineering, 9(1), pp. 49-57.

10. Frt'alová, M., Füri, B., 2017, Application and evaluation of evaporative cooling schemes, Magyar Épületgépészet, LXVI, 2017/10, pp. 22-25.

11. László, K., Miklos, K., 2010, A new calculation procedure to analyse the energy consumption of air handling units. Periodica Polytechnica, Mechanical Engineering, 51(1), pp. 21-26.

12. Lazzarin, R.M., Gasparella, A., 1998, Technical and economical analysis of heat recovery in building ventilation systems, Applied Thermal Engineering, 18, pp. 47-67.

13. Sánta, R., Lászó, G., Igor, F., 2017, Numerical investigation of the heat pump system, Journal of Thermal Analysis and Calorimetry, 130(2), pp. 1133-1144.

14. Hassan, J., Mahmoud, K., Thierry, L., Mohamad, R., 2016, Short review on heat recovery from exhaust gas, TMREES 2016, International Conference on Technologies and Materials for Renewable Energy, Environment and Sustainability; Beirut; Lebanon; 15-18 April 2016; Book Series: AIP Conference Proceedings, DOI: 10.1063/1.4959441. 
15. Mohamad, R., Thierry, L., Mahmoud, K., 2016, Recovering heat from hot drain water - Experimental evaluation, parametric analysis and new calculation procedure, Energy and Buildings, 128, pp. 575-582.

16. Cheng, Z.Shuli, L., Ashish, S., 2017, A review on the air-to-air heat and mass exchanger technologies for building applications, Renewable and Sustainable Energy Reviews, 75, pp. 753-774.

17. Nizovtsev, M.I., Borodulin, V.Y., Letushko, V.N., 2017, Influence of condensation on the efficiency of regenerative heat exchanger for ventilation, Applied Thermal Engineering, 111, pp. 997-1007.

18. Andrzej, J., Sergey, A., Jan, D., Michał, K., Demis, P., 2017, Frost formation and freeze protection with bypass for counter-flow recuperators, International Journal of Heat and Mass Transfer, 108, pp. 585-613.

19. Ali, A., Mazyar, S., 2018, Finding a criterion for the pressure loss of energy recovery exchangers in HVAC systems from thermodynamic and economic points of view, Energy and Buildings, 166, pp. 426 - 437

20. Tibor, P., Viktor, S., 2018, Volumetric Heat Transfer Coefficient in Fluidized-Bed Dryers, Chemical Engineering \& Technology, 41(3), pp. 628-636.

21. Anna, P., Andrzej, J., Demis, P., Sergey, A., 2017, Analysis of freeze protection methods for recuperators used in energy recovery from exhaust air, E3S Web Conference, International Conference on Advances in Energy Systems and Environmental Engineering (ASEE17), 2-5 July, Wroclaw, Poland, 22, pp. 1-8.

22. Menyhart, J., 1977, Handbook of the Building Services, Budapest: Technical Publisher.

23. V. D. Ingenieure, 1997, Heat recovery in heating, ventilation and air conditioning plants, VDI 2071RICHTLINIEN, Düsseldorf.

24. Bartholy, J., 2012, Climatology, EDUTUS College.

25. „Wikipédia,” [Online], 2017, Available: https://hu.wikipedia.org/wiki/Barcelona\#.C3.89ghajlata. 